\title{
Extended Abstracts from the 12th EFAD Conference
}

Berlin, 1-2 November, 2019

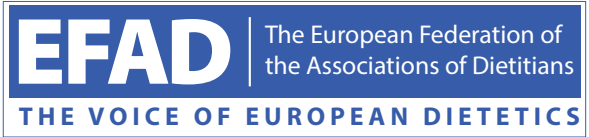

http://efadconference.com 


\section{The Power of Working Together Across Disciplines}

Trude M. Backer Mortensen ${ }^{1}$, Alice Lenihan ${ }^{2}$, Sonja van Oers ${ }^{3}$, Elke Naumann $^{3}$

${ }^{1}$ Oppegård kommune, Norway; ${ }^{2}$ Global Clinical Advisor, Special Olympics Health Promotion; ${ }^{3}$ Research Group Nutrition \& Health, Department of Nutrition \& Dietetics, HAN University of Applied Sciences, The Netherlands

E-Mail E.Naumann@han.nl

Background: Dietitians work in the field of nutrition and dietetics. They work in a variety of work places,such as healthcare settings, community, higher education institutes, governments and food service management. The work of dietitians aims to improve health of European citizens. However, the number of people who would benefit of dietetic care is too large to be covered by dietitians only. In addition, society is changing and new technologies that can be useful for dietitians are emerging. Therefore, there is a need for dietitians to work together with other professionals inside as well as outside health care. The session "The power of working together across disciplines" shows examples of three projects.

Methods: Example 1: PRIMORE is a project initiated by Norwegian researchers and sponsored by the Norwegian research council. Is primary objective is to strengthen the synergy between and the internationalization of Norwegian care research and primary health research. PRIMORE seek to create a European research network to create opportunities for researchers from different disciplines, sectors and countries to develop and share knowledge that will benefit both caring research and primary health care research and, not least, helping to improve the quality of services in Europe.

Example 2: Special Olympics (SO) is a global sports organization for people with intellectual disabilities (ID) that also has a comprehensive offer beyond sports (https://resources.special olympics.org/health/ and https://www.specialolympics.org/ourwork/inclusive-health) [1-2]. Health Promotion, a discipline of Special Olympics Healthy Athletes, focuses on healthy living, healthy lifestyle choices, and nation-specific health issues. Health Promotion offers screenings for blood pressure, health habits, and weight status. The results show that nearly $40 \%$ of the participants are overweight. Therefore, nutrition plays a central role in our program. Health Promotion uses interactive educational tools and displays, motivational literature and demonstrations to raise awareness about the need to improve and maintain an enhanced level of self-care and healthy eating.

Example 3: The health and care sector is in transformation; technology based self-management methods are upcoming but lacking fundamental scientific evidence. There is a need for more pervasive (active) and not persuasive (passive) user-centred innovation in which design has a lot to offer [3]. The FoodSampler consortium is a Dutch Zonmw subsidized collaboration between researchers from design, health sector and e-health business [4]. It aims to explore food informatics strategies to engage people in generating contextual knowledge of their food behavior. The approach combines science and methodologies from both design and health with Mixed Method Research, Research through Design and Living Labs research [5].

Results: Example 1: PRIMORE is integrated in the European Forum for Primary Care (EFPC) and its web-based communication platform PIE. In addition to members in EFPC, researchers and health care professionals with interest research have been invited to participate in the network. Since the launch meeting in March, PRIMORE focusses on three main areas - healthy aging, organization of primary care and mental health. In each of these areas participants currently develop research questions. The communication platform PIE is used for discussion between participants.

Example 2: Special Olympics (SO): Across the SO Health Programs dietitians operationalize interprofessional collaboration and practice working with a variety of health professionals and students to improve athlete health. A partnership between Special Olympics Deutschland and the Association of Dietitians German Association (VDD) has resulted in improved nutrition education, sports nutrition and lifestyle activities among the athletes, coaches and families (https://specialolympics.de/sport-angebote/healthyathletesR-gesunde-athleten/) [6].

Example 3: FoodSampler: Collaboration across professionals working in health and design is valuable. It is also challenging to understand each other correctly, since both areas use different terminologies. Combining knowledge and experiences from both health and design has led to promising insights for development and use of new food registration methods. Involving patients from the beginning of such developments is crucial. Combining expertise and knowledge from health and design also resulted in exploration of new methodologies in research, use of technologies that integrate passive and active ways of reporting, use of datamanagement and better insights in engagement strategies in the use of self-management tools [7]. In the development of a selfmanagement tool, it appears beneficial to involve designers from the beginning of the project and make use of their expertise in design and technologies to engage patients in reporting their food intake.

Conclusions: From the different examples it can be concluded that working together increases the power of action. It increases knowledge and experience in optimizing health care by learning from other disciplines. In addition, working together can be used to develop new research methods and new methodologies for innovative ideas to improve health. Working together with disciplines outside health care settings contributes to develop new perspectives on strategies to improve health.

Disclosure Statement: The authors have no conflicts of interest to declare. 
Author Contribution: All authors had contributed to write this work, and had revised the final version.

Presentations can be consulted on the EFAD website (http:// www.efad.org/en-us/research/research-materials)

Keywords: interdisciplinary work, profession, dietitian, dietician, nutrition, dietetics, practice

\section{References}

1 Special Olympics Health, 2019, https://resources.specialolympics.org/ health/. Accessed 22 October 2019.

2 Special Olympics Inclusive Health, 2019, https://www.specialolympics. org/our-work/inclusive-health. Accessed 22 October 2019.

3 Herrera NR, Davis-Owusu K, Van Oers S, De Van Der Schueren M, Alberts J, Vastenburg M. FoodSampler: Engaging people to contextualise food behaviour: Mixed methods for monitoring choices and triggers of eating habits. In Proceedings of the 12th EAI International Conference on Pervasive Computing Technologies for Healthcare, PervasiveHealth https://doi.org/10.1145/3240925.3240948.

4 Zonmw Create Health, 2019, https://www.zonmw.nl/nl/over-zonmw/ ehealth-en-ict-in-de-zorg/programmas/programma-detail/createhealth/ Accessed 6 November 2019.

5 Foodsampler, 2019, https://studiolab.ide.tudelft.nl/studiolab/foodsampler/ Accessed 6 november 2019.

6 Special Olympics Germany, 2019, https://specialolympics.de/sport-angebote/healthy-athletesR-gesunde-athleten/. Accessed 22 October 2019

7 O'Brien HL, Toms, EG, What is user engagement? A conceptual framework for defining user engagement with technology. Journal of the American society for Information Science and Technology 2008;59(6), 938-955.

\section{Leveraging Video Abstracts in Dietetics: Theory and Skills to Support Dietitians' Effectiveness}

\author{
Power, Brian ${ }^{1,2}$, Joossens, Sofie 3 \\ ${ }^{1}$ UCL Division of Medicine, London; ${ }^{2}$ University College London \\ Hospitals NHS Foundation Trust, London; ${ }^{3}$ University College \\ Leuven - Limburg (UCLL), Belgium \\ E-Mail brian.power@ucl.ac.uk
}

Background/Aims: An abstract is a concise summary of a research paper created to convey a quick overview of a research article [1]. Dietetic practice increasingly recognises the importance of technology in achieving good clinical outcomes [2]. Video abstracts are a branch of technology which go beyond the constraints of written information to convey the nuances of nutrition and dietetics research in a personal, media rich medium [3]. They have the capacity to support dietitians communicate nutrition research information and concepts more effectively and efficiently, and second, to make nutrition and dietetics research more visible, accessible and available for end users [4]. The aims of the workshop were to provide dietitians with the knowledge and skills that will improve the likelihood of success of (video) abstracts in dietetics practice.

Methods: From research evidence we know that research is most effectively disseminated using multiple modes of delivery, ideally with in person interaction. As such, participants at the $12^{\text {th }}$ European Federation of the Associations of Dietitians (EFAD) 2019 conference completed a one hour face-to-face workshop on "Leveraging Video Abstracts in Dietetics: theory and skills to support dietitians' effectiveness". The content of this workshop was innovative, inter-disciplinary and interactive. This workshop consisted of two sessions on 1) abstract writing and 2) video abstract design conducted by two experienced dietitians. Topics discussed included (1) written and video abstracts with applicability in the dietetics setting, (2) the application of video abstracts in clinical practice with consideration to specific target audiences, and (3) methods to enable the design of video abstracts that push the boundaries of nutrition and dietetics work in an engaging mode. Participants reported current challenges in abstract writing and video abstract design. Potential strategies to address these challenges were also discussed. Examples of best practice were presented to foster dietitians' confidence in this area. Lastly, the results of the workshop are summarised here in the form of an extended abstract.

Results: Evidence supporting the relationship between digital technologies and positive outcomes for patients and health professionals is growing. There was general agreement about participants' intentions to use video abstracts for teaching, clinical practice or both. The workshop participants confirmed the relevance of written abstracts and video abstracts to enable the use of research in (their) practice. Participants also highlighted the continuing need for collaborations between Dietitians, Registered Nutritionists, Patients and the public, Academia and Industry in the abstract development process.

Conclusions: Attendance at a conference workshop on abstract writing and video abstract design can serve as a rich ground for building dietitians' competencies and confidence in being able to take an active role in promoting the use of new technologies in healthcare research. This is particularly important for dietitians' professional development as new technologies are set to continue transforming the way we care for and communicate with patients $[5,6]$. This will advance the science and practice of dietetics by producing actionable messages and good practice recommendations to make nutrition and dietetics research more visible, accessible and available for end users [7]. As such, it is anticipated further workshops of this kind will contribute to marked improvements in overall quality of care for patients and the quality and efficiency of dietetic services. To support outputs from this workshop further work is necessary. A dissemination strategy using evidence for translating knowledge into practice could be adopted and implemented. This may include the use of the Scientist Knowledge Translation Plan [8], and wider research evidence on knowledge translation.

Funding: This workshop was supported by the European Federation of the Associations of Dietitians (EFAD) research and evidence-based practice committee.

Disclosure Statement: The authors have no conflicts of interest to declare.

Author Contribution: All authors had contributed to write this work, and had revised the final version.

Presentations can be consulted on the EFAD website (http:// www.efad.org/en-us/research/research-materials)

Keywords: Technology, Communication, Knowledge Translation, Training course
90

Ann Nutr Metab 2020;76:88-105

DOI: $10.1159 / 000505528$
Extended Abstracts 


\section{References}

1 Nagda S. How to write a scientific abstract. J Indian Prosthodont Soc 2013;13:382-3.

2 Chen, J et al: The use of smartphone health apps and other mobile health (mHealth) technologies in dietetic practice: a three country study. J Hum Nutr Diet 2017;30:439-452

3 Giguère, A et al: Printed educational materials: effects on professional practice and healthcare outcomes. Cochrane Database Syst Rev 2012;10:CD004398.

4 Reupert, A: Promoting research through video abstracts. Advances in Mental Health 2017;15(1): 1-3.

5 Chan L, Mackintosh J, Dobbins M: How the "understanding research evidence" web-based video series from the national collaborating centre for methods and tools contributes to public health capacity to practice evidence-informed decision making: mixed-methods evaluation. J Med Internet Res 2017;19(9):e286.

6 Sarkies, MN et al: The effectiveness of research implementation strategies for promoting evidence-informed policy and management decisions in healthcare: a systematic review. Implement Sci 2017;12:132.

7 Spicer S: Exploring video abstracts in science journals: An overview and case study. Journal of Librarianship and Scholarly Communication 2014;2(2):eP1110.

8 Canadian Institutes of Health Research: Guide to knowledge translation planning at CIHR: integrated and end-of-grant approaches. Ottawa 2012; http://www.cihr-irsc.gc.ca/e/45321.html.

\section{Breaking the Boundary of Possibilities with E-Health Tools}

Nicole Erickson ${ }^{1}$, Christoph Riese ${ }^{2}$, Tom Van Daele ${ }^{3}$

${ }^{1}$ Comprehensive Cancer Center CCC ${ }^{\mathrm{LMU}}$, Ludwig-Maximilian

University Clinic, Munich, Germany; ${ }^{2}$ CANKADO Service GmbH, Köln; ${ }^{3}$ Expertise Unit Psychology, Technology \& Society, Thomas More University of Applied Sciences, Antwerp, Belgium

E-Mail Nicole.Erickson@med.uni-muenchen.de

Background: According to the World Health Organization, the term "e-health" describes a broad group of activities and services that employ differing computer applications and electronic means to deliver health-related information, resources, and services [1]. In general e-health tools have the potential to improve diagnosis, treatment, monitoring and management of health, disease, and lifestyle. E-Health tools also present a means to enhance and intensify therapy and better equip patients with support for daily challenges presented by their disease, symptom spectrum, and the therapy itself.

Methods: An exploratory review on E-Health applications in the fields of eating disorders and oncology was conducted. While many different types of E-Health tools are available and technological advances are constantly bringing new solutions to the market, this review focuses on the opportunities available through digital information systems (DISs), and patient support systems (PSSs) with a focus on the areas of oncology and eating disorders. Specifically, these examples will show how, for these diagnoses, where patients and healthcare professionals (HCPs) alike face enormous challenges during therapy and treatment, E-Health applications providing additional methods of delivering care, online documentation of symptoms, and tailored patient recommendations can improve and enhance care.

Results: The initial exploratory review found applications and tools as diverse as the technology itself, ranging from DISs such as websites, and apps to PSSs such as apps, telehealth options, wearables and even virtual reality [2-6]. The scope of what is available is very wide and is not only limited to information and services related to the treatment of cancer and eating disorders, but also covers preventive and rehabilitative measures. It is however, important to note is that, in particular, DISs such as websites and apps in the area of oncology and eating disorders are not always well designed, well monitored, or provide evidence-based nutrition and mental health information. For example, "pro-anorexic" websites, and websites promoting restrictive and not-yet proven dietary interventions for cancer, are still prominent and frequently visited. While quality of contents and delivery is not always ideal, professional solutions developed for, and in collaboration with HCPs, are increasing in availability and serve as a counter balance DISs such as dubious websites and social media exchanges that serve to increase the disease burden on the patients and/or sell quackery. It is therefore important that HCPs become pro-active and familiarize themselves with qualitative systems which are available in their language and recommend them to patients. Furthermore, HCPs should be encouraged to shape and guide the development and use of E-Health tools and applications. Fortunately, this opportunity has begun to be recognized and good practices from non-profit organizations are becoming increasingly available and utilization is increasing.

A growing number of smartphone apps and PSSs are also available, but similarly to the PIS systems, their focus and quality also tends to vary $[2,4-5]$. Nonetheless quality PSSs like Recovery Record for eating disorders and CANKADO for oncology patients are beginning to enter the market and these can also be used as an addition to traditional, face to face, therapy to improve results.

For example, the PRO-React system embedded in CANKADO is an automated symptom-based feedback service. It assists patients in their global health status documentation and dynamically triggers symptom questionnaires while minimizing the documentation burden on both sides. A built-in automated analysis provides patient-tailored recommendations. They are, for example, asked to discuss the symptoms with their physician or to visit them immediately. These patient-reported outcomes are shared in real-time with HCPS. Such PSSs enable more interactive care and patients' needs can be addressed as they change and react to their therapy and environment. Active CANKADO users reveal that the majority of them integrate CANKADO into their daily lives on a daily or weekly basis. A factor enabling successful implementation is an introductory training before applying the E-Health platform. Furthermore, patients report that the regular use helps them to be better prepared for the next consultation and to better understand side-effects.

Further opportunities for improving HCP-lead care through E-Health include DISs and PSSs in the form of wearables. For example, for eating disorders wearables could be used to alert both patients and HCPs to episodes of binge eating [3]. Virtual reality interventions serve as an example to assist in existing body image treatments [4].

Conclusion: As more and more E-Health solutions are available, both patients an HCPS can benefit by harnessing the potential to innovate and improve access to care, quality of care, and to increase the overall efficiency of care delivered. Patients' readiness for E-Health enormously increased over the last few years and they should be steered towards the appropriate tools and applications. Furthermore, HCPs should be encouraged to shape and guide the 
development and use of E-Health tools and applications. Given the increasing acceptance of digital support, E-Health constitutes a helpful supportive care tool for both cancer patients and patients suffering from eating disorders. Most importantly, HCPs need to educate themselves and their patients before the first use to assist them in integrating E-Health support into their daily lives, and thus, ensure that they benefit from this additional support. While initially the possibilities may seem dauting, when utilized effectively -Health tools have been proven to help reduce disease burdens in these populations.

Conflicts of interest: C.Riese is employed by Cankado. All other authors declare no conflict of interest regarding the content of this abstract.

Key Words: E-health, cancer, oncology, mental health, eating disorders

\section{References}

1 World Health Organisation, UN City. From Innovation to Implementation: Health in the WHO European Region. Copenhagen, Denmark: World Health Organisation 2016.

2 Fairburn CG, Rothwell ER: Apps and eating disorders: A systematic clinical appraisal. International J Eat Disord 2015; 48(7):1038-1046.

3 Van Daele T, Vanhoomissen T: Portable technology in mental healthcare. De Psycholoog, Special edition 2015;34-39.

4 Ebel MD, Stellamanns J, Keinki C, Rudolph I, Huebner J. Cancer patients and the internet: a survey among German cancer patients; J Cancer Educ. 2017; 32:503-508

5 Boehme C, Baron von Osthoff M, Frey K, Huebner J. Development of a Rating Tool for Mobile Cancer Apps: Information Analysis and Formal and Content-Related Evaluation of Selected Cancer Apps; Canc Educ; DOI 10.1007/s13187-017-1273-9 • Halwas N, Griebel L, Huebner J. eHealth literacy, Internet and eHealth service usage: a survey among cancer patients and their relatives; J Cancer Res Clin Oncol 2017; 143: 2291-2299

6 Liebl P, Seilacher E, Koester MJ, Stellamanns J, Zell J, Huebner J What cancer patients find in the Internet - the visibility of evidence-based patient information - Analysis of information on German websites; Oncol Res Treat 2015; 38:212-218

\section{Involvement of Dietitians in Primary Care}

Teresa Rodrigues ${ }^{1,3}$, Manuel Moñino
Marianne G. Nijnuis ${ }^{5}$, Luis Matos ${ }^{4}$,
${ }^{1}$ North Regional Administration of Health, Portugal;
${ }^{2}$ Professional Body of Dietitians-Nutritionists of Balearic Islands,
Spain; ${ }^{3}$ ESDN Public Health - EFAD; ${ }^{4}$ Local Health Unit of
Guarda, Portugal; ${ }^{5}$ Platform Patients and Food, the Nederland's
E-Mail teresarodrig@gmail.com

Background: All around the world the population is growing and ageing, resulting in a shift in main diseases, from infectious to non-communicable chronic diseases, in recent decades [1]. The scientific evidence is very clear: food/nutrition is one of the first and most important determinants of health with a major impact on disease protection and health promotion [2]. Although the review of the scientific literature concludes that investment in dietitians provides high returns, the presence of these professionals in primary health care services is not yet a reality in all European countries [3].

Materials and Methods: Present the different experiences of three countries: a) Spain, where a pioneer project integrating dietitians in Primary Care is ongoing;

b) Portugal, where primary care dietitians are a part of the National Health System;

c) Netherlands, focusing on patients' perspective about dietitians in primary care.

\section{Results:}

a) Spain:

Dietitians view individual diets holistically, adapting the advice for specific conditions and diseases following the most recent evidence, improving long-term adherence to diet. On the other hand, primary care is the most suitable setting to do it and a dietitiannutritionist, the more appropriate health professional to provide it [4]. In the Balearic Islands, only 10 clinical dietitians are currently working in 5 of the 7 public hospitals and there are no dietitians in primary care at all. Therefore, the Regional Professional Body of Dietitians-Nutritionists of Balearic Islands (CODNIB) proposed a project to integrate dietitians in the Regional Health Service (RHS), includong 3 phases and dietitian profiles: consultant, teacher and leader of a Dietetic Support Unit [4]. The model would be similar to that of the Netherlands, where primary care professionals give general advice in dietetics and nutrition, and refer their patients to generalist or specialist clinical dietitians, according to previously established criteria [5]. In 2017, CODNIB and RHS signed a contract to address the first phase of the project, producing dietary advice for 47 disease states, for professionals and patients. In light of the call for regional elections, CODNIB began a round of meetings with the political parties represented at the Parliament of Balearic Islands in order to include a proposal in their electoral programs regarding the important role of dietitians in the RHS. In early 2019 the Parliament unanimously approved a proposition not-of-law, made by the party El Pi Proposta per les Illes, for the full integration of dietitians in the RHS, through which the regional government was explicitly urged to continue with the primary care project [6]. In the last meetings with the regional ministry of health, the follow-up of the motion was evaluated and the commitment to create dietetic support units, accelerate the review of the fact sheets and facilitate the training of health professionals for the correct use of information was adopted.

b) Portugal

A healthier population consumes less from the health care system, so health promotion is therefore the basis of any National Health System (NHS), if its purpose is sustainability [1]. Cooperation and integration are key elements of a healthy NHS, putting its focus on prevention rather than treatment [2]. Primary Health Care (PHC) is the best place to conduct proximity interventions that empower individuals and communities for more and better health and nutrition, and dietitians who work there are especially able for successful interventions. Improving the nutritional status of a population should be the priority of every country's public policies [7]. The Portuguese NHC has currently a workforce of around 400 dietitians (300 in hospitals and 100 in PHC), unevenly distributed across the regions and targeting the wrong purpose treatment. This represents a manifestly insufficient number, given the epidemiological profile of the country, but still higher than in most European countries.

c) Netherlands

In the Netherlands access to the dietitian is easy and most times fully reimbursed, providing a real benefit for a patient's health. The treatment of diabetes mellitus type II is a good example of 
collaboration between the general practitioner and the dietitian: preferably the patient is treated with lifestyle intervention and a healthy diet [8]. Despite this good access there is still a lot of work to be done. Doctors often lack nutritional knowledge and thus keep underestimating the importance of nutrition for health. A good example is the increasing interest for blenderized tube feeding: a couple of years ago pediatricians and dietitians were almost all against this way of tube feeding, fearing deficits in nutrients and obstruction of the tube, but many parents have shown benefits of this way of feeding their child, like less vomiting, better stools and better growth [9]. This kind of knowledge has to find its way to the primary care.

Conclusion: With 35.000 dietitians across Europe, dietetics is a growing health care profession. However, dietitians are not consistently represented in health care and still do not exist in half of World Health Organization European Region countries. This lack of integrated health care where dietitians are not a part of the whole health chain can lead to patients not getting appropriate nutrition intervention, ensuing in suboptimal health care and unnecessary high costs. [3] It has been widely reported that optimal nutrition as part of a healthy lifestyle decreases the risk and development of diet-related diseases and can reduce health care costs. Further evidence shows that optimal nutrition - including medical nutrition therapy - as part of a patient's total care also has functional and clinical benefits, with consequential reduction of health care costs. In one analysis, for every $€ 1$ spent on dietary counseling society gets a net $€ 14$ to $€ 63$ return. [3] Nutritional approach in primary care is essential which means that all health professionals should be better informed about the magnitude of a healthy diet and, on the other hand, easy access to the dietitians for patients is absolutely necessary. Also, National Dietetic Association's/Board's are important actors of change in health services and can accelerate policies to improve people's health, by their participation in the legislative public consultation process and making use of institutions through citizen and professional participation channels.

Disclosure Statement: The authors have no conflicts of interest to declare.

Author Contribution: All authors had contributed to write this work, and had revised the final version.

Keywords: Dietitians, Patients, Primary Care.

\section{References}

1 World Health Organization. Global action plan for the prevention and control of Non Communicable Diseases 2013-2020. 2013.

2 World Health Organization. Global strategy on Diet, Physical Activity and Health. 2004.

3 Statement of support for provisional agenda item 5(g): Accelerating primary health care in the WHO European Region: organizational and technological innovation in the context of the Declaration of Astana of the 69th session of the WHO Regional Committee for Europe. September 2019.

4 Aguilar E, Aguilar L, Baladia E, Buhring K, Garroz R, Marqués ME, Martínez-López P, Martínez-Rodríguez R, Osuna I: Evaluación del impacto y coste-beneficio de la inclusión de dietistasnutricionistas en equipos interdisciplinares del Sistema Nacional de Salud: revisión rápida de revisiones sistemáticas. Documento de postura del Consejo General de Colegios Oficiales de Dietistas-Nutricionistas y de la Academia Española de Nutrición y Dietética 2018. Available: https://diamundialdietistanutricionista.org/wp-content/uploads/2018/11/impacto-coste-beneficio.pdf

5 Doctor's Reference Guide to Dietetics. Nederlandse Vereniging van Diëtisten. Available: http://www.artsenwijzerdietetiek.nl
6 Diari de sessions de la Comissió de Salut del Parlament de les Illes Balears. Proposicion No de Llei. RGE15178/18, Incorporació plena del dietista nutricionista al Sistema de Salut de les Illes Balears. Febrer 2019. Available: http://web.parlamentib.es/repositori/PUBLICACIONS/9/comissions/SA-09-075.pdf

7 The World Health Report 2008 - Primary Health Care (Now More Than Ever). 2008.

8 J Neuroendocrinol. 2006; 18(12):883-894. DOI: 10.1111/j.1365-2826. 2006.01492.x

9 Arch Dis Child. 2017 Mar; 102(3):274-278. DOI: 10.1136/archdischild-2016-311030

\section{Eating Habits and Sustainability of the Food Systems}

Manuel Moñino ${ }^{1}$, Andrew Salter ${ }^{2}$, Anna-Karin Quetel ${ }^{3}$, Tanja Draeger de Teran ${ }^{4}$, Marie Spiker ${ }^{5}$

${ }^{1}$ ESDN Public Health - EFAD; Consejo General de Colegios Oficiales de Dietistas-Nutricionistas. Spain; ${ }^{2}$ University of Nottingham, UK; ${ }^{3}$ Swedish Food Agency, Sweden; ${ }^{4}$ WWF, Germany; ${ }^{5}$ Academy of Nutrition and Dietetics Foundation, USA E-Mail mmonyino@gmail.com

Background/Aims: Our current dietary patterns and their impacts on the environment and climate are increasingly becoming a focus of global concern. Changes in our dietary habits offer significant leverage improving the sustainability of the food system and mitigating global threats such as climate change, which is reflected in the Sustainable Development Goals (SDG).

Methods: In this conference session, four presentations about different aspects of sustainability of the food systems were given.

Results: The high rate of population growth, increased life expectancy and improved economic performance in much of the developing world, will increase global demand for nutritious foods, including high quality protein resources [1]. However, current agricultural systems are unlikely to be able to meet the requirements of the global population, without major effects on the environment [2]. Besides, by 2050 only about $2,000 \mathrm{~m}^{2}$ of arable area will be available for each person on this planet to produce agricultural commodities, and today around $70 \%$ of the agricultural land is directly or indirectly devoted to livestock production [3]. Thus, to meet increased global demands there is an urgent need for agricultural, nutritional and food scientists to work together to decrease the reliance of the livestock industry on human-edible crops and to develop sustainable food systems capable of producing alternative sources of high quality protein, acceptable for the a growing, and aging, population.

Despite the substantial and growing evidence confirming that sustainable food systems can be a lever to achieve many of the SDG, only 2 European countries have so far included sustainability in their Food Based Dietary Guidelines (FBDG): Sweden and Germany. However, most FBDGs provide advice aligned with sustainability such as promoting fruits and vegetables, whole grains and nuts and reducing consumption of meat and ultraprocessed food [4]. The Swedish FBDG was among the first in the world to take environmental aspects of food production and consumption into account [5]. The recommendations were developed on the basis of both nutritional science [6] and scientific knowledge of the environmental aspects of the food system [7], related to the Swedish environmental objectives. 
Some European studies [8] show the impact of consumption patterns on the environment and climate, and on the other hand, the significant potential to reduce the impacts of dietary habits. It is important to note the important role of the hospitality sector in achieving a more sustainable food system by adopting Green Public Procurements (GPP), among others actions. Regarding consumer behaviour, small personal changes towards a more sustainable diet can lead to significant impacts and contribute to climate protection and a more sustainable use of our resources.

Given the power of consumers to catalyse food systems change, dietitians are key agents to promote food literacy and guide people towards diets that are both healthy and sustainable $[19,10]$. Dietitians work in diverse practice settings across the food system where they influence the dietary patterns of individuals, institutions, and populations. In addition to their role in shaping healthy and sustainable diets, dietitians can also accelerate progress towards sustainable food and water systems and contribute to the SDGs by leveraging their expertise throughout the food system, including with food producers; along the food supply chain and in food environments; in working on underlying issues that influence food insecurity and water insecurity; and in efforts to reduce waste of food, water, and other resources. Coordinated action across the profession of nutrition and dietetics is needed to ensure that dietitians are aware of these intersecting challenges and equipped to leverage their skills in collaborative, multisectoral efforts.

Conclusions: There are many key factors that could be considered to lead European society towards a more sustainable diet, including: leveraging the expertise of dietitians in multisectoral collaborations, investing in agri-technology, integrating sustainability in FBDGs, and implementing policies and practices that promote sustainability throughout the food system such as GPP and food waste reduction efforts.

Disclosure Statement: The authors have no conflicts of interest to declare.

Author Contribution: All authors had contributed to write this work, and had revised the final version.

Keywords: Healthy Eating, Sustainability, Dietitian, Food System.

\section{References}

1 Salter AM (2018) The effects of meat consumption on global health. Rev. Sci. Tech. Off. Int. Epiz., 37, 47-55.

2 Willett W, Rockstrom J, Loken B et al. (2019) Food in the Anthropocene: the EAT- Lancet Commision on healthy diets from sustainable food systems. Lancet 393, 447-492.

3 Van Zanten HHE, Herrero M, Hal OV, et al. Defining a land boundary for sustainable livestock consumption. Glob Change Biol. 2018;24:41854194. https://doi.org/10.1111/gcb.14321

4 Developments in national healthy and sustainable dietary guidelines. FAO 2016

5 The Swedish dietary guidelines. Find your way to eat greener, not too much and be active. Swedish Food Agency 2015. https://www.livsmedelsverket.se/globalassets/publikationsdatabas/andra-sprak/kostraden/ kostraden-eng-a4-utskriftversion.pdf

6 Nordic Council of Ministers 2014, Nordic Nutrition Recommendations 2012: Integrating nutrition and physical activity https://www.norden. org/en/publication/nordic-nutrition-recommendations-2012

7 Towards Environmentally Sound Dietary Guidelines. Report 9 - 2008. https://bit.ly/32NXaTT; Towards Environmentally Sound Dietary Guidelines - Subreport Fish. Report 10 - 2008. https://bit.ly/341X5fF; Environmental impact of meat, milk and eggs. Report 17 - 2013 https:// bit.ly/2JjLwbR.
8 Dräger de Teran T, Weber K, Meier T, Von Borstel T, Knöbel H, Grauwinkel U (2018): Das Projekt "Essen in Hessen": Implementierung der Themen "Ressourcenschonende Ernährung" und "Vermeidung von Lebensmittelabfällen" in die Außer-Haus-Verpflegung. In: Laux B, Stomporowski S (2018): Nachhaltigkeit in den Bereichen Tourismus, Hotelgewerbe und Ernährung. Schneider Verlag Hohengehren.

9 Vogliano C, Steiber A, Brown K. Linking agriculture, nutrition, and health: The role of the registered dietitian nutritionist. Journal of the Academy of Nutrition and Dietetics. 2015 Oct 1;115(10):1710-4.

10 Tagtow A, Robien K, Bergquist E, Bruening M, Dierks L, Hartman BE, Robinson-O'Brien R, Steinitz T, Tahsin B, Underwood T, Wilkins J. Academy of Nutrition and Dietetics: standards of professional performance for registered dietitian nutritionists (competent, proficient, and expert) in sustainable, resilient, and healthy food and water systems. Journal of the Academy of Nutrition and Dietetics. 2014 Mar 1;114(3): $475-88$.

\section{Obesity Management in Europe}

Hilda Mulrooney ${ }^{1,2}$, Odysseas Androutsos ${ }^{1,3}$, Ellen Govers ${ }^{1,4}$, Antonis Vlassopoulos ${ }^{1,5}$

${ }^{1}$ European Specialist Dietetic Network Obesity of EFAD (European Federation of the Associations of Dietitians); ${ }^{2}$ Kingston University, London, UK; ${ }^{3}$ Department of Nutrition and Dietetics, University of Thessaly, Greece; ${ }^{4}$ Dutch Knowledge Centre for Dietitians on Obesity; ${ }^{5}$ Agricultural University of Athens

E-Mail e.govers112@upcmail.nl

Background and aims: Obesity management in Europe has many facets, all involving the role of dietitians. Our aim was to make an overview of recent developments in public health, childhood obesity, the gaps in the professional approach of dietitians and long term weight management.

Methods: We analysed recent reports on obesity management in different settings in Europe, for adults as well as for children. This abstract is based on the gaps in obesity management we found.

\section{Results:}

Public health

In the UK public health approaches to weight management in the UK deal with the questions: A. What impact might the political situation have on approaches to public health? B. Which approaches is the Obesity Group of the BDA supportive of and why? The environment is recognized as a key influencer of lifestyle behaviours. Nonetheless much public health discourse relates to the changes that individuals must make, in order to improve their health. Currently in the UK a range of public health approaches are used, some of which are aimed at individuals and others at altering the environment. The context is the high prevalence of overweight and obesity affecting the population especially children, so many of the current approaches are aimed at children and families[1]. These include voluntary as well as mandatory approaches such as the recent tax on drinks containing added sugar. Several consultations have been carried out to ascertain healthcare professional and public views on proposed future measures and a Prevention green paper is currently in consultation [2]. 


\section{Interventions in children}

For childhood obesity we focussed on the questions: A. Is there a different approach used in the management of obesity based on the age of the child? B) What is the role of the dietitian-nutritionist in each case? Childhood obesity is currently one of the most important public health challenges globally. The high prevalence of overweight and obesity in paediatric populations and their detrimental effect on health calls for effective interventions for their management [3]. Key approaches and interventions that have been previously implemented to tackle childhood overweight and obesity, highlighting the need to adapt and personalise the elements of the intervention to the specific needs of each target population and child, respectively [4].

Dealing with gaps and dissemination of evidence to dietitians.

Stigma is a large problem in patient care. We therefore searched Pubmed for articles dealing with weight stigma in dietitians and nutritionists. A systematic review on stigma in dietitians made clear stigma is also present in dietitians [5]. Weight-related stigma can negatively affect treatment seeking in terms of weight reduction. Some studies have linked a high BMI to avoidance of health care prevention services or cancellation of appointments due to weight concerns.

Another gap in professional practice is how we set the right targets for weight loss. A literature search came up with one review on health effects of weight loss on comorbidities which showed that a weight loss of 5-10\% makes a meaningful difference for high blood pressure, but for type 2 diabetes a ten kilo weight loss is essential to reach remission. For other comorbidities like PCOS targets are even higher: 10-15\% [6]. The individual patient's targeted health goal should be assessed for response, rather than a prescribed percentage weight loss.

There is still debate over how we know which diet intervention to select for a patient. In weight loss management the general assumption is that eating according to dietary guidelines leads to weight loss. The point is that national dietary guidelines are designed for the general population, based on healthy weight. Most obese patients suffer from insulin resistance, which is the cause of comorbidities varying from hypertension and type 2 diabetes to PCOS and NAFLD and sleep apnoea [7]. To reach lasting success dietitians need to address the cause of health problems through offering the right diet intervention.

Weight loss maintenance.

There is need for clearly establishing the key determinants of weight loss maintenance, and the evidence to support the superiority of specific dietary patterns in weight loss maintenance. Finally, which are the behaviours linked to successful weight loss maintenance? Although weight loss interventions achieving 5-10\% reduction in weight have consistently been shown to be beneficial for health, the majority of patients undergoing a weight loss intervention are at risk of regaining this weight after 6-12 months [8]. Multiple cycles of weight loss and regain have been postulated as determinants of future weight loss success, detrimental changes in body composition and impaired eating behaviours. The effectiveness of different dietetic interventions and the usefulness of various digital and traditional tools in supporting patients during the post weight loss phase is important [9]. The aim of the presentation is to provide information that can be used to design and implement successful weight loss maintenance interventions.

Conclusions: A range of public health approaches are needed to support individuals with attaining and maintaining a healthy weight; a 'health in all policies' approach should be taken to ensure that potential impacts on health, weight and the wider determinants of health are considered in all actions, and evaluations of public health approaches need to be robust and specific.

Childhood is a critical age for efficiently tackling overweight/ obesity. "One-size-fits-all" approaches do not seem to be effective in the management of obesity. Standardizing the decision-making process in selecting the intervention but personalizing the elements of the intervention to the needs of the child may increase the effectiveness of an intervention.

Obesity stigma is still present in dietitians although it is less strong with them than in the general public. It is important to set clear goals for weight loss, based on possible remission of the comorbidities of the individual patient. We need to treat the cause of weight related comorbidities by choosing the right diet intervention.

Weight loss maintenance requires separate and tailor-made dietetic interventions; weight loss maintenance is a complex issue with multiple determinants (sociodemographic, behavioural and psychological), and interventions that promote independence and self-monitoring are important components of every weight loss maintenance programs.

Disclosure Statement: The authors have no conflicts of interest to declare.

Author Contribution: All authors have contributed to write this work, and have revised the final version.

Key words: Obesity, children, public health, stigma, weight maintenance.

\section{References}

1 HM Government (2019) Advancing our health: prevention in the 2020s. Available from: https://assets.publishing.service.gov.uk/government/ uploads/system/uploads/attachment_data/file/81 9766/advancing-ourhealth-prevention-in-the-2020 saccessible.pdf?_ga $=2.3012$ 6393.74990491.1566507824-2140417715.1502556169

2 HM Government (2018) Childhood Obesity: a plan for action, Chapter 2. Available from: https://assets.publishing.service.gov.uk/government/ uploads/system/uploads/attachment_data/file/71 8903/childhood-obesity-a-plan-for-action-chapter-2.pdf HM Government (2016) Childhood obesity: a plan for action. Available from: https://assets.publishing. service.gov.uk/government/uploads/system/uploads/attachment_data/ file/54 6588/Childhood_obesity_2016__2_acc.pdf?_ga =2.96206490.74 990491.1566507824- 2140417715.1502556169

3 Barlow SE, Expert Committee. Expert Committee recommendations regarding the prevention, assessment and treatment of child and adolescent overweight and obesity. Summary report. Pediatrics 2007 (120): 164-192.

4 Androutsos O et al. (2014). Designing and implementing teachers' training sessions in a kindergarten-based, family-involved intervention to prevent obesity in early childhood. The ToyBox-study. Obes Rev. 2014;15 Suppl 3:48-52. doi: 10.1111/obr.12182.

5 Jung FU, Luck-Sikorski C, Wiemers N, Riedel-Heller SG. Dietitians and Nutritionists: Stigma in the Context of Obesity. A Systematic Review. PLoS One. 2015 Oct 14;10(10):e0140276. doi: 10.1371/journal. pone.0140276.

6 Ryan DH, Ryan Yockey S. Weight Loss and Improvement in Comorbidity: Differences at 5\%,10\%,15\%, and Over. Curr Obes Rep. 2017 June ; 6(2): 187-194. doi:10.1007/s13679-017-0262-y.

7 Sainsbury E, Kizirian NV, Partridge SR, Gill T, Colagiuri S, Gibson AA. Effect of dietary carbohydrate restriction on glycemic control in adults with diabetes: A systematic review and meta-analysis. Diabetes Research and Clinical Practice 139 (2018): 239-252. 
8 Varkevisser RDM et al. (2019) Determinants of weight loss maintenance: a systematic review. Obesity Reviews 20:171-211. https://doi. org/10.1111/obr.12772

9 Holmes WS et al. (2019) Impact of digital technologies for communicating messages on weight loss maintenance: a systematic literature review. European Journal of Public Health 29(2):320-328. https://doi. org/10.1093/eurpub/cky171

\section{Malnutrition and Dietary Treatment in Older Adults - a Conference Report}

\author{
Harriët Jager-Wittenaar $^{1,2}$, Stacey Jones ${ }^{3}$, Elisabet Rothenberg ${ }^{4}$, \\ Dorothee Volkert ${ }^{5}$ \\ ${ }^{1}$ Research Group Healthy Ageing, Allied Health Care and \\ Nursing, Hanze University of Applied Sciences, Groningen, The \\ Netherlands; ${ }^{2}$ Department of Maxillofacial Surgery, University \\ of Groningen, University Medical Center Groningen, Groningen, \\ The Netherlands; ${ }^{3}$ Faculty of Health and Life Sciences, Coventry \\ University, Coventry, United Kingdom; ${ }^{4}$ Food and Meal Science, \\ Kristianstad University, Kristianstad, Sweden; ${ }^{5}$ Institute for \\ Biomedicine of Aging, Friedrich-Alexander-Universität Erlangen- \\ Nürnberg, Nürnberg, Germany \\ E-Mail ha.jager@pl.hanze.nl
}

Background/Aims: With an ageing population worldwide, pressure on health and social care systems grows. Strategies to prevent age-related conditions as malnutrition, sarcopenia, and frailty are therefore of ultimate importance, to enable older adults remaining physically and mentally active and independent as long as possible. Good nutrition plays a significant role in maintaining and improving functioning. The aim of the conference session was to 1) elucidate and discuss nutritional challenges faced and strategies to improve nutritional intake and nutritional status among older adults, and 2) to share knowledge and best practices gained from both national and international (research) projects on nutrition and ageing conducted in Europe.

Methods: In this conference session, three presentations about different aspects of malnutrition in older persons were given. Firstly, an overview of current practices in different European Countries to prevent malnutrition in older adults were presented and discussed. Data were collected via the European Specialist Dietetic Network for Older Adults who reported on the most recent statistics, guidelines and practice for screening, prevalence and interventions for identifying, preventing and treating malnutrition. Secondly, the relationship between dietary intake, physical performance (gait speed and hand grip strength) and body composition (dual energy x-ray absorptiometry) in two cohorts from the Gothenburg H70 Birth Cohort Studies, i.e., one Swedish cohort at age 70 (born in 1944) and one Swedish cohort at age 85 (born in 1930) [1] were discussed. Thirdly, a range of strategies to support adequate nutrition in older adults were discussed.

Results: Information was provided by representatives from Spain, The Netherlands, United Kingdom, Switzerland, Greece, Turkey, and Portugal, which identified commonalities in practice as well as variations that were specific for each country. Mandatory nutritional risk screening is not in place for every country and for some countries, even when malnutrition screening is mandatory the rate of screening uptake remained low. Many countries reported staffing/dietetic capacity as a limitation, and the need for dietitians to raise awareness of the importance of nutrition amongst other medical and allied health professionals was raised. There is consensus that dietitians should be regarded as integral members of the multidisciplinary team and whilst there were some examples of good practice, there is still room for improvement in this area. A variety of screening tools are used and reported malnutrition prevalence varied between countries, however with the latest GLIM consensus on the diagnosis criteria for malnutrition, this may encourage consistency in criteria in the future.

Data from the Gothenburg H70 Birth Cohort Studies [1] showed good dietary intake in relation to recommendations [2], although intake for some nutrients were somewhat lower in the 85 -year olds compared to the 70 -year olds. In both cohorts vitamin $\mathrm{D}$ was the nutrient with highest proportion of low intakes. Among the 70 -year olds, alcohol intake had increased significantly indicating changes in lifestyle over time. Significant differences were found in prevalence of low muscle mass, slow self-selected walking speed, and hand grip strength, with a higher proportion having sarcopenia among the 85 -year olds compared to the 70 -year old ( $3 \%$ vs. 55\% respectively) [3]. Differences were also found in meal patterns among 85 year-olds in risk of malnutrition compared to those without with lower meal frequency and less snack meals/day among those in risk of malnutrition.

Strategies to support adequate nutrition range from strategies to identify those in need of nutritional support to strategies regarding the provision of nutrition [4]. As an important prerequisite, all older persons should be routinely screened for malnutrition in regular intervals in order to identify an existing risk early. Various validated screening tools specifically for older persons are available for different healthcare settings [5]. Potential risk factors or causes of malnutrition, e.g. chewing or swallowing problems, medication side effects or depression, need to be identified and eliminated as far as possible [4]. Direct dietary strategies to support adequate intake include the recommendation or provision of energy and nutrient dense food and enriched meals in an appealing and appetizing way. Particular attention should be paid to sensory characteristics, adequate texture and food variety, always considering individual likes and dislikes. Dietary restrictions should generally be avoided since they may limit food choice and eating pleasure and thus bear the risk of limiting dietary intake [4].

Besides regular main meals, snacks should be available as needed. Furthermore, older persons should be encouraged to share their mealtimes with others and eat in a pleasant, relaxed atmosphere. In case of dementia, finger food may help to maintain independent eating and allow for eating while walking for persons who are constantly pacing. Depending on individual resources and need of assistance for shopping, preparing meals and eating, adequate support should be arranged. If oral nutrition is insufficient or impossible despite all these efforts, e.g., in case of dysphagia, enteral and parenteral nutrition should be taken into consideration [4].

As often several persons - relatives as well as different health care professionals - are involved in nutritional care, communication and close cooperation of these persons is important to ensure consistent approaches and avoid double effort.

Conclusions: Older adults are at increased risk of malnutrition, which in turn is related to poor health outcomes. Nutritional interventions aim to maintain autonomy through physical independence, preventing disability, and to ensure quality of life among
Extended Abstracts 
older adults. Nutritional care and support of older adults at risk or affected by malnutrition is thus an important public health concern, but adequate structures and strategies to prevent and treat malnutrition are not implemented everywhere. Future efforts should aim to put adequate nutritional care into practice as an integral part of geriatric healthcare in all settings in all countries.

Disclosure Statement: The authors have no conflicts of interest to declare.

Author Contribution: all authors had contributed to write this work, and had revised the final version.

Key words: ageing, older adults, nutrition, dietary intake, malnutrition

\section{References}

1 Rydberg Sterner T, Ahlner F, Blennow K, Dahlin-Ivanoff S, Falk H, Havstam Johansson L, et al. The Gothenburg H70 Birth cohort study 2014-16: design, methods and study population. Eur J Epidemiol 2019;34(2):191-209.

2 Samuelsson J, Rothenberg E, Lissner Lauren, Eiben Gabriele, Anna Z, Ingmar $S$. Time trends in nutrient intake and dietary patterns among five birth cohorts of 70-year-olds examined 1971-2016 Results from the Gothenburg H70 Birth Cohort Studies, Sweden. Nutrition Journal 2019 [In press].

3 Wallengren O, Bosaeus I, Frändin K, Rothenberg E, Skoog I. Comparison of the 2010 and 2018 diagnostic criteria for sarcopenia by the European Working Group on Sarcopenia in Older People (EWGSOP) in Swedish Elderly. Clinical Nutrition 2019;38(Suppl1):S1-S353.

4 Volkert D, Beck AM, Cederholm T, Cruz-Jentoft A, Goisser S, Hooper L, Kiesswetter E, Maggio M, Raynaud-Simon A, Sieber CC, Sobotka L, van Asselt D, Wirth R, Bischoff SC. ESPEN guideline on clinical nutrition and hydration in geriatrics. Clin Nutr 2019;38: 10-47.

5 Power L, de van der Schueren MAE, Leij-Halfwerk S, et al. Creation of a scoring system to rate malnutrition screening tools used in older adults in community and healthcare settings - a MaNuEL study. Clinical Nutrition $2018 ; 24: 1-13$.

\section{Human Milk Composition: Overview of Systematic Reviews}

Marqués María ${ }^{1}$, Baladia Eduard ${ }^{1,2}$, Martínez Patricia ${ }^{1,3}$, Martínez-Rodríguez Rodrigo ${ }^{1}$, Buhring Kristian ${ }^{1,4}$, Camacho Saby ${ }^{1,5}$, Aguilar Barrera Eliud ${ }^{1,6}$, Aguilar Luis ${ }^{1}$, Osuna Iván ${ }^{1,7}$, Garroz Roland ${ }^{1}$

${ }^{1}$ Red de Nutrición Basada en la Evidencia, Academia Española de Nutrición y Dietética, Pamplona, Spain; ${ }^{2}$ Centro de Análisis de la Evidencia Científica, Academia Española de Nutrición y Dietética, Pamplona, Spain; ${ }^{3}$ Grupo de Investigación Techné, Ingeniería del conocimiento y del Producto, Universidad de Granada, Granada, Spain; ${ }^{4}$ Universidad Andrés Bello campus Concepción, Chile; ${ }^{5}$ Nutrir México, Mexico; ${ }^{6}$ Instituto Politécnico Nacional, CICS-UMA, Ciudad de México, Mexico; ${ }^{7}$ Instituto Nacional de Enfermedades Respiratorias, Ciudad de México, Mexico E-Mail e.baladia@rednube.net.

Background: The World Health Organization (WHO) recommends exclusive breastfeeding during the first six months of age, and continuing until at least two years. Human milk is determinant for infant development and growth and offers many short and long-term health benefits [1]. The composition of breast milk may be of interest when milk cannot be offered directly from the breast, as it helps to estimate the necessary intake according to the infant's requirements. The nutrient content fluctuates, particularly for preterm and term milk, the stage of lactation and between feeds $[1,2]$. This fact makes the determination of its average composition difficult. Additionally, there is a wide variability in laboratory techniques used to analyse the samples, for instance, bomb calorimetry or calculation methods for energy [2].

The objective of the present overview is to collect all the available evidence systematically compiled on the average composition of breast milk in terms of energy, protein, lipid, lactose, iodine and phosphorus for mature milk and colostrum.

Methods: An overview of systematic reviews was carried out. Only systematic reviews of milk composition were eligible for inclusion. Searches were conducted in The Cochrane Library, PubMed and Epistemonikos electronic databases. The Epistemonikos database collects systematic reviews from 10 databases (Cochrane Database, PubMed, Embase, CINAHL, PsycINFO, LILACS, DARE, Campbell library, JBI, EPPI library) with the collaboration between humans and machine learning. The last search was carried out in June 2019. Please find below the search engine constructed for PubMed: (("Breast Feeding”[Mesh] OR "Breast Feeding"[tiab] OR "Breastfeeding"[tiab] OR "Breastfed"[tiab] OR (("Lactation"[Mesh] OR "Lactation"[tiab] OR "lactating”[tiab]) AND (women[tiab] OR human[tiab] OR woman[tiab] OR mother[tiab] OR mothers[tiab] OR infant[tiab] OR infants[tiab] OR child[tiab] OR childs[tiab])) OR "Milk, Human"[Mesh] OR "Human Milk"[tiab] OR “Breast Milk”[tiab])) AND (("Meta-Analysis" [Publication Type] OR "Meta-Analysis as Topic"[Mesh] OR "Network Meta-Analysis"[Mesh] OR “MetaAnalysis"[tiab] OR "Meta-Analyses"[tiab] OR “The Cochrane database of systematic reviews"[Jour]) OR (systematic[sb] OR "systematic review"[tiab] OR "systematic reviews"[tiab] OR "Systematic reviews"[Jour] OR "JBI library of systematic reviews"[Jour]) OR ("umbrella review"[tiab] OR "umbrella reviews"[tiab] OR "umbrella systematic review"[tiab] OR "overview of systematic reviews"[tiab] OR (overview[ti] AND (Cochrane[ti] OR "The Cochrane database of systematic reviews"[Jour])))).

A double-blind peer selection was conducted to select systematic reviews. The risk of bias will be assessed using the AMSTAR 2 tool.

Results: This overview is within its early stages and preliminary results can only be provided. 2147 potentially eligible systematic reviews were retrieved, of which, 41 were full-text screened. 22 analysed the macro and micronutrient composition of mature milk (MILK) and colostrum (CAL) as primary outcomes, while 19 analysed the content of contaminants, microbiota and drugs as secondary outcomes. The mean content and variability of energy $(\mathrm{kcal} / \mathrm{dL})$, protein $(\mathrm{g} / \mathrm{dL})$, lipids $(\mathrm{g} / \mathrm{dL})$, lactose $(\mathrm{kcal} / \mathrm{dL})$, iodine $(\mu \mathrm{g} / \mathrm{dL})$, calcium $(\mathrm{mg} / \mathrm{dL})$ and phosphorus $(\mathrm{mg} / \mathrm{dL})$ was estimated in 3 systematic reviews (table 1). Additionally, in other 12 systematic reviews, oligosaccharides, fatty acid profile, amino acid profile, lactoferrin, vitamin B12, and vitamin E have been estimated (data not available yet).

Conclusions: There is a significant amount of systematic reviews that evaluate the composition of breast milk and colostrum. Key nutrients, contaminants, microbiota and drugs are evaluated, and the average content of nutrients can be determined with an acceptable precision. Regarding iodine, despite that the main 
indicator of iodine intake is the median urinary concentration, in infants, due to the difficulty of sample collection, the determination of iodine in breast milk is sufficiently reliable to determine the iodine status [3].

However, because there is a wide variability in the analytical techniques and the representativeness of the sample, it is still uncertain if the results obtained could be translatable. More homogeneous studies are still required. In addition, the overlap in the use of the same studies in the different systematic reviews should be evaluated, and the results of individual studies which have not been added yet to date should be meta-analysed.

Funding: There is no funding for this work.

Disclosure Statement: All the authors declare they may have a potential risk of bias since they strongly support breastfeeding in their profession and family. Additionally, RMR works in a company which develops and distributes infant formulas and follow on formulas, as well as, nutritional supplements for pregnancy (pecuniary COI). LA is writing an informative book on healthy habits, which may have academic COI and if it is eventually published, it may have a pecuniary COI as well. Finally, RG works in a company which develops and distributes oral nutritional supplements for oral and enteral feeding, and nutritional supplements not aimed to pregnant women or infants.

Author Contribution: All authors had contributed to write this work, and had revised the final version.

Keywords: Human milk, colostrum, breastfeeding, lactating mothers, nutritional composition.

\section{References (only references of systematic reviews of data} shown in table 1)

1 Yang T, Zhang L, Bao W, Rong S. Nutritional composition of breast milk in Chinese women: a systematic review. Asia Pac J Clin Nutr. 2018;27(3):491-502

2 Gidrewicz DA, Fenton TR. A systematic review and meta-analysis of the nutrient content of preterm and term breast milk. BMC Pediatr. 2014;14:216

3 Nazeri P, Kabir A, Dalili H, Mirmiran P, Azizi F. Breast-Milk Iodine Concentrations and Iodine Levels of Infants According to the Iodine Status of the Country of Residence: A Systematic Review and MetaAnalysis. Thyroid. 2018;28(1):124-38

\section{Domestic Cooking, BMI, and Factors Determining Women's Involvement - TDHS- 2013 Study Findings}

Z. Begum Kalyoncu' ', Turkan Merdol', Gonca Yildirim 1,2, Ozlem Cetiner ${ }^{1,3}$, Bartu Eren Gunesliol ${ }^{1,2}$, Ayhan Dag ${ }^{4}$, Tugba Adali ${ }^{5}$

${ }^{1}$ Atilim University, Faculty of Health Sciences, Dept. of Nutrition and Dietetics, Kizilcasar Mahallesi, Incek Golbasi, Ankara, Turkey; ${ }^{2}$ Acibadem University, Faculty of Health Sciences, Dept. of Nutrition and Dietetics, Icerenkoy, Atasehir, Istanbul, Turkey; ${ }^{3}$ Ankara University, Faculty of Health Sciences, Dept. of Nutrition and Dietetics, Ankara, Turkey; ${ }^{4}$ International Cyprus University, Faculty of Health Sciences, Dept. of Nutrition and Dietetics, Lefkosa, Northern Cyprus; ${ }^{5}$ Hacettepe University, Institute of Population Studies, Dept. of Social Research Methodology,

Beytepe, Ankara, Turkey

E-Mail z.begum.kalyoncu@gmail.com

Background/Aims: Cooking and home food preparation have increasingly been considered as a public health opportunity in the face of augmented rates of overweight and obesity in the developed, high-income countries [1]. "Domestic cooking”, used interchangeably with "home cooking", refers to actions required for preparing hot or cold foods at home, including combining, mixing and often heating ingredients [2], which is typically associated with women despite the shifting developed country demographics [3]. Domestic cooking was shown to be positively associated with higher diet quality and positive health outcomes among adults in certain studies $[4,3]$; whereas other ones reported either no association or suggest that longer meal preparation time to be associated with higher energy intake and obesity among women $[5,6]$. Since domestic cooking's complexity that is attributable to geographical and demographical variations between studies affects diet and health inconsistently, more research is needed to assess the effect of domestic cooking on women's BMI $[7,8]$. Also, the complex interactions between determinants and health-related outcomes of domestic cooking is also relatively understudied due to methodological challenges [2]. Furthermore, determinants of domestic cooking have been understudied for the context of

Table 1. Mean content and variability of energy, lipids, lactose, iodine, calcium, phosphorus was estimated in 3 systematic reviews

\begin{tabular}{|c|c|c|c|c|c|c|}
\hline \multirow[t]{2}{*}{ Nutrient } & \multicolumn{2}{|c|}{ Colostrum (CAL) } & \multicolumn{2}{|c|}{ Mature milk (MILK) } & \multirow[b]{2}{*}{$\mathrm{N}$} & \multirow[t]{2}{*}{ Systematic Review } \\
\hline & Mean & Variability & Mean & Variability & & \\
\hline \multirow[t]{2}{*}{ Protein $(\mathrm{g} / \mathrm{dL})$} & 1.64 & SD: \pm 0.32 & 1.22 & SD: \pm 0.12 & 35 & Yang T et al. (2018) \\
\hline & 2.00 & $\mathrm{SD}: \pm 0.90$ & 1.00 & SD: \pm 0.10 & 30 & Gidrewicz DA et al. (2014) \\
\hline Fat $(g / d L)$ & 2.36 & $\mathrm{SD}: \pm 1.17$ & 3.39 & $\mathrm{SD}: \pm 1.24$ & 35 & Yang T et al. (2018) \\
\hline Iodine $(\mu \mathrm{g} / \mathrm{L})$ & 152.0 & CI 95\%: 106.2 to 198.7 & 71.5 & CI $95 \%: 51.0$ to 91.2 & 57 & Nazeri P et al. (2018) \\
\hline Calcium (mg/dL) & 26.00 & SD: \pm 6.00 & 27.00 & SD: \pm 3.00 & 30 & Gidrewicz DA et al. (2014) \\
\hline Phosphate (mg/dL) & 11.00 & SD: \pm 3.00 & 14.00 & SD: \pm 3.00 & 30 & Gidrewicz DA et al. (2014) \\
\hline
\end{tabular}

SD: Standard Deviation / CI 95\%: Confidence Interval at 95\% / N: Number of studies included 
developing countries as well. Therefore, the aim of this study was to evaluate the effect of domestic cooking on women's BMI and then elucidate the factors that determine women's involvement in domestic cooking for the context of Turkey.

\section{Methods:}

\section{Study Design and Data Source}

The data source for the present study came from publicly available Turkey Demographic and Health Survey 2013 (TDHS-2013) dataset. TDHS-2013 was conducted by Hacettepe University Institute of Population Studies with the contributions of Turkish Ministries of Development and Health [9]. TDHS-2013 was a nationally representative, cross-sectional household survey, in which the respondents are selected from urban and rural areas of major five regions of the country through weighted, multi-stage, stratified cluster sampling. Information was collected from women of reproductive age (15-49 years) via individual face-to-face questionnaires. Data on various sociodemographic and socio-economic indicators, fertility, maternal and child heath, reproductive health, and women's status along with the anthropometric measures of women and children were collected. Further details of the study design and methods of the TDHS-2013 have been described previously [9]. For the present study, secondary data analysis on women's data was performed to evaluate the effect of domestic cooking on women's BMI and then elucidate the factors that determine women's involvement in domestic cooking for the context of Turkey through the nationally representative TDHS-2013 Survey. For the current analysis pregnant participants and those with missing information on domestic cooking were excluded. In total 8204 participants' data were used and women were grouped into two categories as either "involved with domestic cooking" if they reported to primarily cook either themselves only or with others in the household or "not involved with cooking" if cooking was done by others. The difference in BMI ((weight $\left.(\mathrm{kg}) /(\text { height }(\mathrm{m}))^{2}\right)$ depending on cooking involvement was analyzed with CSGLM procedure. Then, the factors that impact the odds of being involved in cooking were assessed with bivariate logistic regression analysis. Estimates were adjusted for education (DHS categories of 1 . No education/primary incomplete, 2. First level primary, 3. Second level primary, 4. Highschool and higher) household wealth level (DHS categories of Wealth Index; 1. Very poor, 2. Poor, 3. Normal, 4. Rich, 5. Very rich), smoking (categories of 1 . No smoking, 2. Irregular smoking, 3. Regular smoking), alcohol intake (categories of 1 . No intake, 2. Irregular intake, 3. Regular intake), physical activity (categories of 1. None, 2. Irregular, 3. Regular), marital status (categories of 1. Married, 2. Single), age (in years), and parity (total children ever born). All the analyses were conducted using the complex sample procedures of the SPSS software version 21 (IBM Corp., 2013, Armonk, NY, USA). TDHS-2013 study was conducted according to the guidelines laid down in the Declaration of Helsinki and all procedures (data collection and the questionnaires) involving research study participants were approved by the Hacettepe University's Ethics Committee. Informed consent was obtained from all study participants at first contact. Since this study analyzed the publicly available TDHS-2013 data with no personally identifiable information, no further institutional review board approval was required.

Results: In total 8204 participants' data were used and $70.8 \%$ of women in the TDHS sample were reported to be primarily involved in cooking. Those who were involved in cooking had significantly higher BMI than women who were not involved
(28.09 vs. $23.55, \mathrm{p}<0.001)$. Wealth status explained the highest odds of being involved in cooking for low household wealth women $\left(e^{\beta}=2.236 ; p<0.0001\right)$ compared with high household wealth counterparts (Table 1) after adjusting for education, physical activity, marital status, smoking, alcohol intake, age, parity, and BMI. Additionally, holding all the covariates constant, being involved with cooking was associated with odds of having $2 \%$ higher BMI level $(\mathrm{p}=0.016)$ as opposed to being single $\left(\left(\mathrm{e}^{\beta}=0.040 ; \mathrm{p}<0.001\right)\right.$ compared with married women (Table 1 ).

Conclusions: For the context of Turkey, higher participation of meal preparation and cooking appears to be associated with having higher BMI for women; low household wealth level and being married explaining the level of involvement the most. Despite having similar percentage of women being involved with cooking in Turkey compared to many high income countries (around 70\%), there was a decreasing trend of cooking with increasing levels of wealth, which was different from developed countries where cooking could be perceived as a luxury requiring more time, money, and skills [10]. These differences of social determinants of cooking in Turkey could be used to enhance public health nutrition interventions and/or programs (nutrition assistance programs, healthy cooking guidance) to cook healthfully and promote cooking among people of different levels of income.

Funding: There is no funding for this work.

Conflicts of Interest: Z. Begum Kalyoncu declares that she has no conflict of interest. Turkan K. Merdol declares that she has no conflict of interest. Gonca Yildirim declares that she has no conflict of interest. Ozlem Cetiner declares that she has no conflict of interest. Bartu Eren Gunesliol declares that he has no conflict of interest. Ayhan Dag declares that he has no conflict of interest. Tugba Adali declares that she has no conflict of interest.

Ethical Standards Disclosure: This study used the publicly available Turkey Demographic Health Survey - 2013 (TDHS2013) data with no personally identifiable information, therefore no further institutional review board approval was required. TDHS-2013 was conducted according to the guidelines laid down in the Declaration of Helsinki and all procedures (data collection and the questionnaires) involving research study participants were approved by the Hacettepe University's Ethics Committee. Inform ed consent was obtained from all study participants at first contact.

Author Contribution: All authors had contributed to write this work, and had revised the final version.

Keywords: cooking, demographic survey, women's health, Turkey, BMI

\section{References}

1 Reicks M, Trofholz AC, Stang JS, Laska MNJJone, behavior. Impact of cooking and home food preparation interventions among adults: outcomes and implications for future programs. 2014;46(4):259-76.

2 Mills S, White M, Brown H, Wrieden W, Kwasnicka D, Halligan J, et al. Health and social determinants and outcomes of home cooking: a systematic review of observational studies. 2017;111:116-34.

3 Wolfson JA, Bleich SN, Smith KC, Frattaroli SJA. What does cooking mean to you?: perceptions of cooking and factors related to cooking behavior. 2016;97:146-54.

4 Wolfson JA, Bleich SNJPhn. Is cooking at home associated with better diet quality or weight-loss intention? 2015;18(8):1397-406.

5 Chu YL, Addo OY, Perry CD, Sudo N, Reicks MJA. Time spent in home meal preparation affects energy and food group intakes among midlife women. 2012;58(2):438-43.

6 Sobal J, Hanson KJA. Family dinner frequency, settings and sources, and body weight in US adults. 2014;78:81-88. 
Table 1. Bivariate logistic regression model showing adjusted associations between being involved with cooking and health \& social determinants

\begin{tabular}{|c|c|c|c|}
\hline Variables & Odds Ratio $\left(e^{\beta}\right)$ & \%95 CI for Odds Ratio & p-value \\
\hline Intercept & 0.429 & $(0.258,0.713)$ & 0.001 \\
\hline Very poor & 2.236 & $(1.666,3.001)$ & $<0.0001$ \\
\hline Poor & 2.057 & $(1.531,2.764)$ & $<0.0001$ \\
\hline Normal & 1.619 & $(1.227,2.137)$ & 0.001 \\
\hline No education/Primary incomplete & 0.674 & $(0.457,0.993)$ & 0.046 \\
\hline First level primary & 1.394 & $(1.041,1.868)$ & 0.026 \\
\hline Second level primary & 0.708 & $(0.567,0.883)$ & 0.002 \\
\hline \multicolumn{4}{|c|}{ Physical activity (Ref category: No physical activity) } \\
\hline Regular & 1.154 & $(0.881,1.512)$ & 0.296 \\
\hline Irregular & 1.119 & $(0.929,1.348)$ & 0.235 \\
\hline Irregular consumption & 0.769 & $(0.504,1.173)$ & 0.222 \\
\hline \multicolumn{4}{|l|}{ Smoking (Ref category: No smoking) } \\
\hline Regular smoking & 1.692 & $(1.270,2.254)$ & $<0.0001$ \\
\hline Irregular smoking & 1.166 & $(0.771,1.763)$ & 0.467 \\
\hline Age (in years) & 1.091 & $(1.075,1.108)$ & $<0.0001$ \\
\hline Parity (number of total children ever born) & 0.855 & $(0.778,0.940)$ & 0.001 \\
\hline BMI (weight $\left.(\mathrm{kg}) /(\text { height }(\mathrm{m}))^{2}\right)$ & 1.021 & $(1.004,1.039)$ & 0.016 \\
\hline Nagelkerke $\mathbf{R}^{2}=0.641 ; p<0.001$, Classification & & & \\
\hline
\end{tabular}

7 Kegler MC, Alcantara I, Haardörfer R, Gazmararian JA, Ballard D, Sabbs DJJone, et al. The influence of home food environments on eating behaviors of overweight and obese women. 2014;46(3):188-96.

8 Mills S, Adams J, Wrieden W, White M, Brown HJPhn. Sociodemographic characteristics and frequency of consuming home-cooked meals and meals from out-of-home sources: cross-sectional analysis of a population-based cohort study. 2018;21(12):2255-66.

9 Studies HUIoP. 2013 Turkey demographic and health survey. Hacettepe University Institute of Population Studies, TR Ministry of ...; 2014.

10 Taillie LSJNj. Who's cooking? Trends in US home food preparation by gender, education, and race/ethnicity from 2003 to 2016. 2018;17(1):41.

\section{Evaluation of Dietary Intake in Acutely III Geriatric Patients in a District Hospital in Northern Germany}

Fuhse Katrin ${ }^{1}$, Ruhs Franziska', Mühlberg Raika', Sautter Lea Franziska ${ }^{1}$, Ramminger Sara' , Keil Jens-Peter ${ }^{2}$, Valentini Luzia'

${ }^{1}$ Bachelor Course Dietetics for Dietitians, University of Applied Sciences Neubrandenburg, Neubrandenburg, MecklenburgWestern Pomerania, Germany

${ }^{2}$ Dept. of Geriatrics, Rehabilitation and Palliative Care, DietrichBonhoeffer-Klinikum, Neubrandenburg, Mecklenburg-Western Pomerania, Germany

E-Mail kfuhse@gmx.de

Background/Aims: Geriatric patients are often unable to meet their energy requirements during hospital stays, which might contribute to high prevalence of malnutrition seen in this group [1]. Up to two thirds of older patients in acute care and rehabilitation hospitals are at nutritional risk or malnourished [2]. Moreover, own previous investigations in acutely ill geriatric patients show reduced protein and energy intakes even in well-nourished geriatric patients [3].

Therefore, the present study aimed at re-evaluating the extent to which recommended dietary intakes of macro- and micronutrients cannot be met by acutely ill geriatric patients during hospital stay.

Methods: This cross-sectional study was conducted once weekly totaling six complete days from $8^{\text {th }}$ October to $16^{\text {th }}$ November 2018 on a geriatric ward in a district hospital in Northern Germany. Detailed weighed food records were performed on one day during hospital stay in 24 mostly well-nourished geriatric patients (15 (63\%) female, $82 \pm 6.2$ years, BMI $29.8 \pm 8.1 \mathrm{~kg} / \mathrm{m}^{2}, 18 / 24$ NRS$2002<3)$. Nutrient intake was calculated using PRODI 6 compact (Nutri-Science GmbH, Freiburg, Germany). Energy requirements were calculated using BASAROTs, PAL of 1.3 and stress factors. Protein requirements were set on $1.2 \mathrm{~g} / \mathrm{kgBW} / \mathrm{d}$. An adapted body weight was used for obese patients $(n=10)$. Body composition was determined via bioelectrical impedance analysis using seca mBCA 525 (seca gmbh \& co. kg., Hamburg, Germany). Diet quality was measured using the EPIC Healthy-Eating-Index. NutritionDaylike questionnaires were used to collect information on anthropometric data, medical data as well as eating behavior in general and at day of investigation. 
Results: Contrary to expectations, $63 \%(n=15)$ of the patients met their recommended energy intake, calculated with $10 \%$ tolerance to total energy requirements. Mean caloric-deficit among patients not covering their energy requirement was $519 \pm 267 \mathrm{kcal} / \mathrm{d}$ $(n=9)$. Nevertheless, 92\% $(n=22)$ did not achieve the recommended protein requirements for geriatric nutrition. Mean deficits were $0.4 \pm 0.2 \mathrm{~g} / \mathrm{kgBW} / \mathrm{d}$ or $31.8 \pm 16.3 \mathrm{~g} / \mathrm{d}$ respectively. Intake of carbohydrates was significantly reduced and accordingly, intake of fat was significantly increased (see table 1). This led to a macronutrient distribution of $13 \%$ protein, $45 \%$ fat and $42 \%$ carbohydrates. Fibre intake was significantly reduced as well as fluid intake. Intake of iodine, iron, folic acid and calcium were low and did not comply with ESPEN guideline on clinical nutrition and hydration in geriatrics (see table 1). Overall, 38\% ( $n=9)$ described an unintentional weight loss during the last three months. Even though $79 \%(n=19)$ were satisfied with hospital catering, $71 \%(n=17)$ did not finish the meal off. Although $63 \%(n=15)$ were interrupted while eating, patients did not perceive it as reason for leftovers. Instead 65\% $(n=11)$ of participants with leftover food $(n=17)$ stated too high volume of the meals. Only $12 \%(n=2)$ each reported lower appetite than usual or not tasting food as reason and $6 \%(n=1)$ each indicated chewing and swallowing problems or 'did not feel well'. However, on the day of investigation only $13 \%(n=3)$ had medical conditions associated with food intake and only $25 \%(n=6)$ felt to eat less than usually at home. Nutritional quality was rated as "needs improvement" ( $62.5 \pm 12.0$ points). Low energy and protein intake were not associated with care level, dental status or polymorbidity. High energy intake was positively associated with phase angle $\left(r_{p}=0.524\right.$, $\mathrm{p}=0.012$ ). Participants at nutritional risk showed a significantly lower energy intake (NRS $<3$ vs NRS $\geq 3$ : $1760 \pm 249$ vs. $1228 \pm 406$ $\mathrm{kcal} / \mathrm{d}, \mathrm{p}=0.009)$ as well as significantly lower protein intakes $(\mathrm{NRS}<3$ vs. $\mathrm{NRS} \geq 3: 0.9 \pm 0.2$ vs. $0.6 \pm 0.1 \mathrm{~g} / \mathrm{kgBW} / \mathrm{d}, \mathrm{p}=0.007)$ and $\mathrm{a}$ significantly lower phase angle than participants without nutritional risk (NRS $<3$ vs. $N R S \geq 3: 4.5 \pm 0.6^{\circ}$ vs. $\left.3.6 \pm 0.6^{\circ}, p=0.014\right)$. Low absolute protein intake tends to result in low phase angle $\left(r_{p}=0.422\right.$, $\mathrm{p}=0.051)$ and was associated with lower NRS-Score $\left(\mathrm{r}_{\mathrm{s}}=-0.589\right.$, $\mathrm{p}=0.002$ ).

Conclusions: Despite sufficient energy intake, recommendations for protein and micronutrient intake could not be met by predominantly well-nourished acutely ill geriatric patients. Therefore, adapted nutrient composition, especially increased nutrient density and higher amounts of protein might be meaningful for hospital catering in acute care geriatrics.

Table 1. Comparison of nutritional intake and requirement

\begin{tabular}{llll}
\hline $\mathrm{n}=24$ & $\begin{array}{l}\text { Intake } \\
\text { mean } \pm \mathrm{SD}\end{array}$ & $\begin{array}{l}\text { Requirement } \\
\text { mean } \pm \mathrm{SD}\end{array}$ & $\mathrm{p}$-value \\
\hline Energy in kcal & $1627 \pm 371$ & $1694 \pm 341$ & 0.607 \\
Protein in g & $54.9 \pm 15.4$ & $83.8 \pm 15.8$ & 0.001 \\
Protein in g/kg bw/d & $0.8 \pm 0.2$ & $1.2 \pm 0$ & $<0.001$ \\
Fat in g & $79.0 \pm 23.7$ & $53.2 \pm 10.5$ & 0.021 \\
Carbohydrates in g & $173.0 \pm 51.5$ & $197.6 \pm 41.9$ & 0.019 \\
Fibre in g & $16.6 \pm 8.9$ & $21.2 \pm 4.3$ & 0.002 \\
Fluids in ml & $1448 \pm 477$ & $1750 \pm 198$ & 0.032 \\
Calcium in mg & $747 \pm 243$ & $1000 \pm 0$ & $<0.001$ \\
Iron in mg & $8.0 \pm 3.9$ & $10.0 \pm 0.0$ & 0.015 \\
Folate in $\mu \mathrm{g}$ & $162.1 \pm 66.7$ & $300.0 \pm 0.0$ & $<0.001$ \\
Iodine in $\mu \mathrm{g}$ & $72.0 \pm 32.9$ & $180.0 \pm 0.0$ & $<0.001$ \\
\hline
\end{tabular}

12th EFAD Conference
Disclosure Statement: The authors have no conflicts of interest to declare.

Author Contribution: All authors had contributed to write this work, and had revised the final version.

Key words: dietary intake, geriatrics, acute care, nutritional quality, hospital catering

\section{References}

1 Volkert D, Beck AM, Cederholm T, Cruz-Jentoft A, Goisser S, Hooper L, Kiesswetter E, Maggio M, Raynaud-Simon A, Sieber CC, Sobotka L, van Asselt D, Wirth R, Bischoff SC: ESPEN guideline on clinical nutrition and hydration in geriatrics. Clin Nutr 2019;38(1):10-47.

2 Kaiser MJ, Bauer JM, Rämsch C, Uter W, Guigoz Y, Cederholm T, Thomas DR, Anthony PS, Charlton KE, Maggio M, Tsai AC, Vellas B, Sieber CC, for the Mini Nutritional Assessment International Group: Frequency of Malnutrition in Older Adults: A Multinational Perspective Using the Mini Nutritional Assessment. J Am Geriatr Soc 2010;58(9): 1734-1738.

3 Engelskirchen J, Beritsch L, Heitland S, Helwig L, von der Weiden N, Seegler S, Ramminger S, Keil JP, Valentini L. Energy intake of geriatric patients is inadequate and correlates with care dependency. Abstract presentation EFAD meeting 2018, Rotterdam.

\section{Nutrient Profile Models in the Assessment of Breakfast Cereals}

\author{
Casas Camí, Assumpta ${ }^{1}$, Gelonch Nicolau, Anna ${ }^{1}$, \\ Ibáñez Alguero, Cristina' , Pérez Garrich, Cristina', \\ Jakszyn Filosof, Paula ${ }^{3}$, Carrillo-Álvarez Elena ${ }^{2}$ \\ ${ }^{1}$ Faculty of Health Sciences Blanquerna - Universitat Ramon \\ Llull (Barcelona, Spain); ${ }^{2}$ Global Research on Wellbeing (GRoW) \\ research group; ${ }^{3}$ Cancer Epidemiology Research Program, \\ Catalan Institute of Oncology and Bellvitge Biomedical Research \\ Institute, Barcelona, Spain \\ E-Mail aumptacc@blanquerna.url.edu
}

Background/Aims: Nutrient profile models (NPM) are described by the WHO as the science of classifying food by its nutritional composition, with the aim of orientating informed food choices. Due to the increasing prevalence of non-transmissible chronic diseases (NCDs) several nutrient profile models have been issued by various institutions, each of which assesses processed food products in a slightly different way.

Breakfast cereals are amongst the most consumed process food products and citizens often view them as a healthy option, while more dietitians are discouraging their regular consumption.

The main objective of this study was to compare the performance of five nutrient profile models from different region: Nutriscore, Nutrient Profile Model-UK, Health Star Rating System-Australia, Panamericana Model and WHO-model, when applied in the analysis of breakfast-cereals.

Methods: Five breakfast-cereal available in Spanish supermarkets were analysed. The selection was made following criteria of popularity, health claims and ecological origin. The five NPM were applied to each cereal brand following the steps indicated by each model's guidelines. Results obtained were synthesized in a comparative table based on their score and interpretation according to each NPM. 
Results: The five NPM follow different steps to determine the quality of each product in relation to NCDs, all of them expressing the results per $100 \mathrm{~g}$ or $100 \mathrm{ml}$.

Nutriscore is represented by a five-letter picture, from A to E with a colour scale that goes from green to red, being A and green the healthiest option. It considers total energy, saturated fatty acids, sugar and sodium as bad nutrients and protein, fiber and the percentage of fruits, vegetables or pulses of the processed product as positive nutrients. [1] Although it is a very visual and easy method to understand, it has some limitations: it does not consider as a positive quality the content of unsaturated fats and it is not possible to differentiate added sugar from the one that is naturally present. In our sample, four out of five cereals obtained a $\mathrm{C}$ grade, and one was classified as a D.

The UK model was created with the objective of avoiding television adverts of non-healthy food during the period of time when children usually watch TV. It classifies food as "healthy" or "less healthy", considering the same positive and bad nutrients as $\mathrm{Nu}$ triscore. This method is very useful for TV media workers because it is easy to understand and they only need to distinguish those food products that can be announced from the ones that cannot be. [2] The main disadvantage is that protein and fiber are considered as beneficial nutrients, so products as cookies or cereals enriched with protein or fiber could be considered as healthy, although the high content of added sugar, salt and saturated fatty acids. In this case, it defines four of five cereals as "less healthy" and one as "healthy".

The Australian model uses a scale from half a star to five stars, being five stars the healthiest. It classifies food as dairy or no dairy products and differentiates the same healthy and unhealthy nutrients as the previous two. [3] The advantages are similar as the $\mathrm{Nu}$ triscore: it is very visual and easy to understand for the general population. The main disadvantage is that the use of this models is not compulsory for all brands. It rates three out of five cereal brands with 3 stars and the other two with 3,5 stars.

The Panamerican model was created to label every packed food with signs alerting the high quantity of some nutrients such as sugar and other sweeteners, sodium, total fat, saturated fatty acids and trans fatty acids. [4] The main advantage of this model is that it considers the number of sweeteners contained, apart from sugar. Additionally, it is only focused on negative characteristics of the product so, in this case, if a product is enriched with fibre or protein, it will not affect the result. As for the disadvantages, it does not provide a scale of quality so the consumer may have more difficulties to choose the healthiest option. This model indicates that four out of five cereals brands are high in sugar and two out of five are high in sodium.

Finally, the WHO Regional Office model is developed with the same purpose as the NPM from UK. Food is classified in twenty categories, each one with a limit value assigned for total fat, saturated fat, total sugars, added sugars, sweeteners, salt and energy, that cannot be exceeded. If it does, it will be classified as no suitable to be advertised. [5] The main advantage of this method is that it is very fast to apply and that all processed food as juices, sodas and pastries are directly considered as no suitable. It considers the amount of trans fat that a product contains but the main disadvantage is that lots of processed food do not give information about this quantity. In this case, only one cereal brand is classified as suitable.

Conclusion: The analysis done in this study shows how most breakfast-cereals consumed in Spain do not comply with recommendations to promote health, regardless of the NPM used to assess them. Nutrient profile models are tools that can help decreasing the burden of disease by informing consumers about the healthiness of food products. It is important to emphasise that they do not categorise lifestyles, but only food products. In the same way, it is indispensable to interpret each NPM results in the context of the purpose for which it has been created.

Disclosure Statement: The authors have no conflicts of interest to declare.

Author Contribution: All authors had contributed to write this work, and had revised the final version.

Key words: Nutrient Profile Models, Nutriscore, Nutrient Profiling Model UK, Australia Health Star Rating, Breakfast-cereal

\section{References}

1 Buzyn A, Travert S, Griveaux MB. Nutri-Score. Dossier de Presse [Internet]. França: Ministère des Solidarités et de la Santé, Ministère de l'Agriculture et de l'Alimentation i Ministère de l'Économie et des Finances; 2017 [cited 19/06/2019]. Available from: http://webcache. googleusercontent.com/search?q=cache:okUq1rV3VZIJ:agriculture. gouv.fr/telecharger/87510\%3Ftoken\%3D537276c9f22122955add7292a bbcce0d+\&amp;cd=1\&amp;hl= ca\&amp;ct=clnk\&amp;gl=es

2 Gov.UK. Department of Health. Nutrient Profiling Technical Guidance [Internet].Londres: Department of Health; January 2011 [cited 19/06/2019]. Available from :https://assets.publishing.service.gov.uk/ government/uploads/system/uploads/attachment_data/file/216094/ dh_1234 92.pdf

3 Health AGD of. About Health Star Ratings. [cited 19/06/2019]; Available from: http://healthstarrating.gov.au/internet/healthstarrating/publishing.nsf/Content/About-health-stars

Table 1. Results for each breakfast-cereal brand analysed by the 5 NPM

\begin{tabular}{|c|c|c|c|c|c|}
\hline & Corn flakes & Special K & $\begin{array}{l}\text { Muesli } \\
\text { Hacendado }\end{array}$ & Chocapic Bio & Smacks \\
\hline Nutriscore & $\mathrm{C}$ & $\mathrm{C}$ & $\mathrm{D}$ & $\mathrm{C}$ & $\mathrm{C}$ \\
\hline $\begin{array}{l}\text { Nutrient profile } \\
\text { model (UK) }\end{array}$ & Healthy & Less healthy & Less healthy & Less healthy & Less healthy \\
\hline $\begin{array}{l}\text { Health Star Rating } \\
\text { System (Australia) }\end{array}$ & 3 stars & 3,5 stars & 3 stars & 3,5 stars & 3 stars \\
\hline Panamericana4 & High in salt & $\begin{array}{l}\text { High in sugar } \\
\text { High in salt }\end{array}$ & High in sugar & High in sugar & High in sugar \\
\hline WHO Model & Suitable & No suitable & No suitable & No suitable & No suitable \\
\hline
\end{tabular}


4 Consejo directivo de la OPS. Modelo de perfil de nutrientes de la organización Panamericana de la Salud [Internet]. Washington: OMS; 2016 [cited 19/06/2020]. Available from: http://iris.paho.org/xmlui/bitstream/handle/123456789/18622/9789275318737_spa.pdf

5 World Health Organization, Regional Office for Europe. WHO Regional Office for EuropeNUTRIENT PROFILE MODEL[Internet].Copenhagen: World Health Organization, 2015 [cited 19/06/2020]. Available from: http://www.euro.who.int/_data/assets/pdf_file/0005/270716/ Nutrient-children_web-

\section{Development of an Abbreviated Food Frequency Questionnaire for Assessing Dietary Iron Intake in Schoolchildren: Lessons Learnt}

Charlene Goosen ${ }^{1}$, Renée Blaauw ${ }^{1}$

${ }^{1}$ Division of Human Nutrition, Department of Global Health, Stellenbosch University, Cape Town, South Africa

E-Mail charleneg@sun.ac.za

Background/Aims: Globally children carry the highest burden of anaemia with at least $60 \%$ of anaemia attributed to iron deficiency [1]. Knowledge of usual food intake is fundamental in dietary interventions for iron deficiency anaemia, especially in lowincome settings where staple diets are plant-based [2]. Obtaining dietary intake information from children is challenging since the process is cumbersome and children may disengage, leading to poor quality data $[3,4]$. School-aged children spend a substantial amount of time away from home which necessitates self-reporting of food consumption during this period. While caregivers can assist with dietary intake reporting, they cannot solely act as a proxy for reporting complete intake. This study was nested within a clinical trial and aimed to assess dietary iron intake in 8 to 13-year old children from low-income areas in Cape Town, South Africa. Considering the potential pitfalls of dietary assessment in this age group, we regarded participant engagement and active participation as key drivers to determine the most appropriate dietary assessment method, and in the subsequent develop process of an abbreviated quantified food frequency questionnaire (QFFQ).

Methods: The three main considerations for determining the most appropriate dietary assessment method were the study setting, the nutrients of interest and the age of the study population [4-6]. The clinical trial was performed at the Family Centre for Research with Ubuntu (FAMCRU) in Tygerberg Hospital, Cape Town and had a predetermined study schedule and time frame. The key nutrients of interest encompassed iron and nutrients involved with iron absorption and metabolism, namely animal protein, calcium, vitamin $\mathrm{A}$, vitamin $\mathrm{C}$, zinc and fibre. For this age group, a succinct method with appropriate strategies to improve engagement and active participation were deemed ideal. Given the single interaction advantage, epidemiological appropriateness [5-7], and potential for adaptation to a context-specific abbreviated questionnaire, we identified an interviewer-administered iron QFFQ with the child participant-caregiver pair as the best method to obtain the required data within our study setting. A well-developed QFFQ reflects the nutrients of interest and study population's habitual intake [5]. In addition to these characteristics, we prioritized careful planning of the questionnaire structure and a variety of interesting portion size estimation aids in support of participant engagement and active participation [5,7]. In the absence of an appropriate QFFQ validated for the specific study population and considering the timeline of the clinical trial, we followed a methodical approach driven by one experienced key worker. We used a multiphase approach to develop an abbreviated iron OFFQ and to establish its face and content validity. We engaged individually with key informants from the community, facilitated a larger group discussion with community representatives, performed pilot interviews, and consulted with senior diet methodology researchers.

Results: Following the implementation of the QFFQ in the clinical trial $(n=180)$, we reflected on the chosen strategies aimed at collectively supporting participant engagement and active participation (Figure 1). For this age group, interviewing the child participant and caregiver together provided comprehensive and accurate reporting and created a comfortable space for the child to engage with the interviewer. The QFFQ followed a logical but strategic order of categorised items. Careful positioning of foods received from the School Nutrition Program throughout the questionnaire and listing relevant but less affordable products between frequently eaten foods successfully supported continuous engagement and interview momentum. The first category of the QFFQ included frequently eaten staple foods that required active participation to indicate portion sizes. The children were interested in the different dietary intake assessment aids and eagerly engaged when prompted to use them to describe their portion sizes. For example, if a child reported cereal consumption, we asked him or her to indicate which of a selection of bowls best resembled the bowl used for cereal consumption. The interviewer would then empty a weighed portion of the reported cereal into the bowl with further comparison and quantification as needed. Similarly, weighted food portion photographs and drawings elicited interest and the children enjoyed using them to indicate which of a series of portion sizes best resembled their portion size. Using one experienced key worker to drive the development and implementation of the QFFQ proved to be invaluable in obtaining rounded knowledge and understanding of the study population's eating habits and food nuances. We used the development phase to learn the local terms for popular foods and to gain insights into their purchasing preferences when they received money to buy their own food or snacks. This led to better prompting ability and increased relatability, good interaction between the child participants and interviewer and greater interview success.

Conclusions: Using one experienced key worker and a methodical approach for developing an abbreviated QFFQ reflecting the nutrients of interest and study population's habitual intake, together with strategies aimed at optimizing participant engagement and active participation, contributed to the successful collection of dietary iron intake information from school-aged children from a low-income setting.

Acknowledgements: We sincerely thank Prof E WentzelViljoen, Prof M Faber, and Prof E Kunneke for their insights into dietary assessment in the local context.

Funding Sources: This paper presents independent research that was supported by the Thrasher Research Fund and the L'OréalUNESCO For Women in Science Sub-Saharan Africa Fellowship.

Disclosure Statement: The authors have no conflicts of interest to declare. 


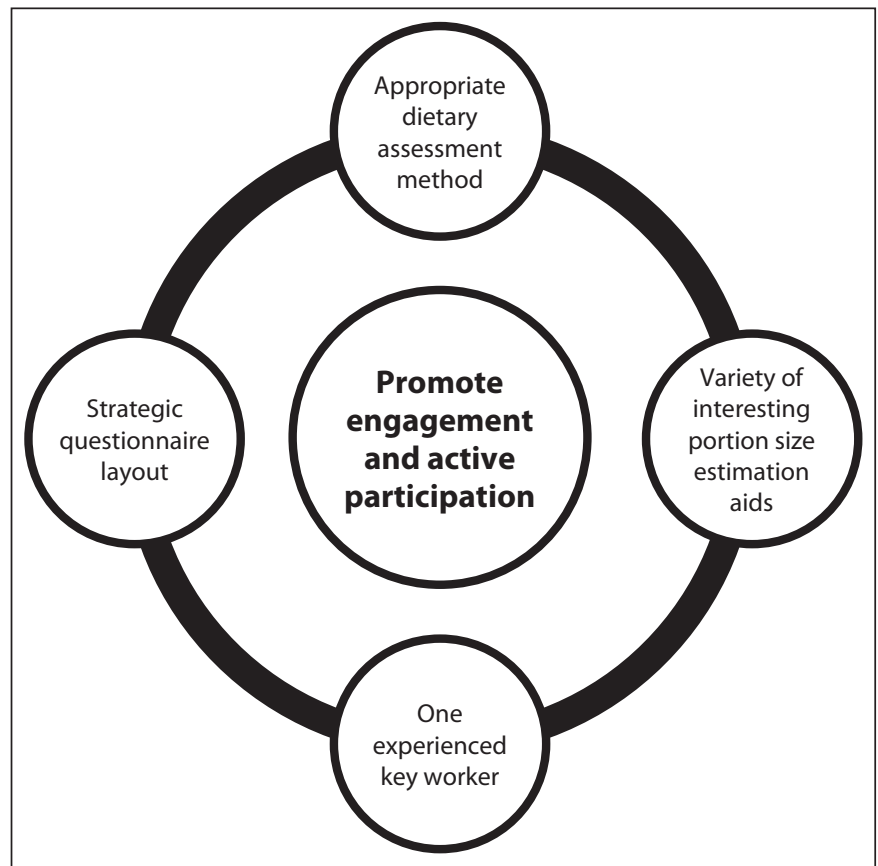

Fig. 1. Participant engagement and active participation as key drivers for interview success.

Author Contributions: CG and RB conceptualized and designed the study. CG led the development process, implemented the QFFQ and wrote the manuscript. RB acted as supervisor and critically reviewed the manuscript.

Keywords: Iron, children, food frequency questionnaire

\section{References}

1 Kassebaum NJ: The global burden of anemia. Hematol Oncol Clin North Am 2016;30(2):247-308.

2 Gibson RS, Hotz C, Temple L, Yeudall F, Mtitimuni B, Ferguson E: Dietary strategies to combat deficiencies of iron, zinc and vitamin A in developing countries: Development, implementation, monitoring and evaluation. Food Nutr Bull 2000;21(2):219-31.

3 Gibson RS: Chapter 5: Measurement errors in dietary assessment. Principles of Nutritional Assessment. Oxford University Press 2005:105-28.

4 Zingoni C, Norris SA, Griffiths PL, Cameron N: Studying a population undergoing nutrition transition: A practical case study of dietary assessment in urban South African adolescents. Ecol Food Nutr 2009; 48(3):178-98.

5 Cade J, Thompson R, Burley V, Warm D: Development, validation and utilisation of food-frequency questionnaires - a review. Public Health Nutr 2002; 5(4):567-87.

6 Food and Agriculture Organization of the United Nations: Dietary Assessment: A resource guide to method selection and application in low resource settings. FAO: Rome 2018 DOI: 10.1016/B978-0120883936/50075-0

7 Gibson RS: Chapter 3: Measuring food consumption of individuals. Principles of Nutritional Assessment. Oxford University Press 2005: $41-64$.

\section{Role of a Dietitian in a Specialist Memory Assessment and Support Service - Improving brain health}

Emma Fox 1, Sarah White ', Eimear Digan ${ }^{1}$, Sinead Feehan ${ }^{1}$, Cathy McHale ${ }^{2}$, Joshi Dookhy ${ }^{2}$, Sean Kennelly ${ }^{2}$

${ }^{1}$ Nutrition and Dietetic Department, Tallaght University Hospital, Belgard Square North, Tallaght, Dublin 24, Ireland

${ }^{2}$ Department of Age-related Healthcare, Tallaght University Hospital, Belgard Square North, Tallaght, Dublin 24, Ireland

E-MailEmma.Fox@tuh.ie

Background/Aims: Dementia cases are rising nationally due to our ageing population [1] and it is associated with a multitude of nutritional consequences. Both obesity and malnutrition are strongly implicated in the progression of cognitive decline and are a significant burden of disease [2,3]. From time of diagnosis onwards, nutritional intervention is important to prevent nutritional consequences and improve patient outcomes [4]. The relationship between dementia severity and nutritional risk is well documented, with significant nutritional decline and weight loss being experienced in this cohort [4]. ESPEN guidelines on nutrition in dementia highlight the importance of nutritional support at diagnosis to prevent further nutritional deterioration [4]. Individuals in this population frequently experience changes to their eating habits and preferences and research shows adherence to healthy eating guidelines declines prior to dementia diagnosis, thus further emphasising the need for nutritional support at such early stages [4]. There can be a significant proportion of obese and overweight in this cohort. This a significant nutritional and medical concern as those with higher BMI's experience greater risks of adverse health consequences, pressure sores, frailty, reduced mobility and cognitive impairment $[5,6]$. Studies have revealed that those who were overweight and obese in midlife had an increased relative risk of developing several forms of dementia than those who were of normal weight $[5,7]$. The aim of this study was to identify the nutritional and physical profile of those attending a tertiary memory assessment and support service in Ireland and to identify both the risk factors for cognitive decline and nutritional concerns in this population. In addition to this the aim was to highlight the importance and need for a dietitian in a specialist memory assessment and support service.

Methods: In order to highlight the role and need for a dietitian, a retrospective analysis of patients attending a tertiary memory assessment and support service from 2018 to 2019 was performed. Demographic, anthropometric and cognitive data was compiled from the case note review which was gathered routinely by the nurses. A frailty score was assigned using the validated Rockwood Clinical Frailty Scale. The clinical frailty scale ranged from 1 (very fit) to 9 (terminally ill), with a score of 5 or more indicating frailty. Nutritional status was assessed using the Mini Nutritional Assessment short-form (MNA) and biochemical laboratory results. A score of 12-14 indicated normal nutritional status, a score of 8-11 indicated that they were at risk of malnutrition and $<8$ showed that they were malnourished. The diagnostic tool used for cognitive assessment was the Clinical Dementia Rating Global Score (CDR) where the patient could be rated as having 'none', 'questionable', 
'mild', 'moderate' or 'severe' dementia based on a carer or family member's answers. Cambridge Behavioural Inventory Revised (CBI-R) was used to identify eating habits related to dementia as observed by the carer. Each eating habit is rated as occurring 'never', 'a few times a month', 'a few times per week', 'daily' or 'constantly' and the sum of these scores out of a possible score of 16 represents their normal or abnormal eating habits.

Results: A significant proportion of this population were overweight (41.2\%) and obese (18.6\%). Nearly half the population were either at risk of malnutrition (44.1\%) or malnourished (3.9\%). In this cohort, $18.6 \%$ were characterised as frail. Only one individual had a severe CDR, $19.2 \%$ had a moderate CDR and $28.2 \%$ had a mild CDR. Half (50.5\%) of participants had some level of abnormal eating habits, with $14.3 \%$ of patients having mildly disordered eating habits or worse. Higher prevalence of malnutrition, frailty and higher CDR and disordered eating habit scores was associated with increased age. Up to $60 \%$ of those with normal nutritional status had a CDR of none or questionable. All malnourished patients had a CDR of 0.5 or higher and the only individual with a severe CDR was nutritionally at risk. As MNA score worsened, the incidence of robust individuals decreased linearly. Prevalence of frailty increased as CDR score worsened. Of those with a mild CDR, 70\% were overweight or obese. All patients with a CDR score of none had slight or no disordered eating behaviours. Those with high CBI-R eating habit scores generally had lower CDR scores. As CBI-R eating habits scores worsened, the proportion of malnourished individuals and those at risk of malnutrition increased.

Conclusion: Patients attending the memory service are experiencing a multitude of nutritional challenges such as disordered eating habits, overweight and obese BMIs, malnutrition risk and frailty which are associated with cognitive decline and worse health outcomes [2]. Research indicates that improvements in diet in the older adult may be effective in improving executive functions and maintaining global cognition [3]. Nutritional support and dietetic input as part of the post-diagnostic care-pathway is required to promote brain health and mitigate this unnecessary decline.
Disclosure Statement: The authors have no conflicts of interest to declare.

Author Contribution: All authors had contributed to write this work, and had revised the final version.

Key words: Dementia, Malnutrition, Frailty, Tertiary Memory Assessment and Support Service, Body Mass Index.

\section{References}

1 Pierce M, Cahill S, O‘Shea E. Prevalence and Projections of Dementia in Ireland, 2011-2046. (Accessed March 5 2019, https://www.genio.ie/system/files/publications/Dementia_Prevalence_2011_2046.pdf).

2 Livingston G, Sommerlad A, Orgeta V, Costafreda SG, Huntley J, Ames D, Ballard C, Banerjee S, Burns A, Cohen-Mansfield J, Cooper C. Dementia prevention, intervention, and care. The Lancet 2017;390: 2673-2734.

3 Lehtisalo J, Levälahti E, Lindström J, Hänninen T, Paajanen T, Peltonen M, Antikainen R, Laatikainen T, Strandberg T, Soininen H, Tuomilehto J. Dietary changes and cognition over 2 years within a multidomain intervention trial-The Finnish Geriatric Intervention Study to Prevent Cognitive Impairment and Disability (FINGER). Alzheimer's \& Dementia 2019;15: 410-417.

4 Volkert D, Chourdakis M, Faxen-Irving G et al. ESPEN guidelines on nutrition in dementia. Clin Nutr. 2015;34:1052-73.

5 Anstey KJ, Cherbuin N, Budge M et al. Body mass index in midlife and late-life as a risk factor for dementia: a meta-analysis of prospective studies. Obesity Reviews 2011;12: 426-437.

6 Gonçalves Damascena K, Batisti Ferreira C, Dos Santos Teixeira P et al. Functional capacity and obesity reflect the cognitive performance of older adults living in long term care facilities. Psychogeriatrics 2017;17: 439-445.

7 Singh-Manoux A, Dugravot A, Shipley M et al. Obesity trajectories and risk of dementia: 28 years of follow-up in the Whitehall II Study. Alzheimer's \& Dementia 2018;14: 178-186. 